\title{
Asemi-Empirical Study of the Adsorption of Some Organic Pollutants on Modified Iraqi Clays
}

\author{
Khulood A. S. Al-Saade \\ Huda N. AL-Ani \\ Department of Chemistry, College of Science, University of Baghdad, Jadiriya, \\ Baghdad, Iraq \\ E-mail: khulood_abid@yahoo.com
}

Received 26/1/ 2015

Accepted 14/6/ 2015

(1) (8)

EY No ND This work is licensed under a Creative Commons Attribution-NonCommercialNoDerivatives 4.0 International Licens

\section{Abstract:}

In this work semi-empirical method (PM3) calculations are carried out by (MOPAC) computational packages have been employed to calculate the molecular orbital's energies for some organic pollutants. The long- chain quaternary ammonium cations called Iraqi Clays (Bentonite - modified) are used to remove these organic pollutants from water, by adding a small cationic surfactant so as to result in floes which are agglomerates of organobentonite to remove organic pollutants. This calculation which suggests the best surface active material, can be used to modify the adsorption efficiency of aniline, phenol, phenol deriviatives, Tri methyl glycine, ester and pecticides, on Iraqi Clay (bentonite) by comparing the theoretical results with experimental results achived in previous experimental studies between some organic pollutants and modified bentonite by (1- Hexadecyl pyridinium bromide) (HDPYBr). The theoretical calculation is made by using three surface active materials [1- (Hexadecyl pyridinium bromide) (HDPYBr), (1,12- Dipyridiniododecane dibromide) (DPYDDBr 2 ) and Hexadecyl trimethyl ammonium bromide (HDTMA)]. Using (HDTMA) leads to the best adsorption efficiency for most pollutants involved in this study. The enthalpy of formations, dipole and energy of molecular orbitale HOMO and LUMO energies levels are calculated for all pollutants and the three surface active materials.

Key words: PM3 Semi-Empirical Method, Adsorption, Quaternary Ammonium Salts, Iraqi Clays (Organ-Bentonite).

\section{Introduction:}

Modified Iraqi Clays are profitably effective to remove toxic environmental contaminants[1]. Clay materials can be modified by using chemical/ physical treatment like natural aluminosilicate clays which are highly hydrophilic and show avery low adsorption, for hydrophobic organic contaminants by modifying these surfuses by adding long chain organic compounds[2], can achieve high sorption [3-6]. Semiempirical methods have a long useful history in solid- state chemistry, spanning several decates [7]. Indeed, an approximate molecular orbital calculation lays the foundation for 
subsequent $a b$ initio methods at the time when computing resources do not permit more accurate techniques to be applied [8]. studying the molecular modeling of adsorption of poly (L-Lysine) onto silica glass is done by using two approaches : an AM1 semi-empirical moleculer orbital method and an MM3 molecular mechanics method to investigate the structural configuration for poly (LLysine) [9]. Different investigations on the adsorption and heterolytic dissociation of $\mathrm{H}_{2} \mathrm{O}$ and $\mathrm{H}_{2}$ molecules on a $(\mathrm{ZnO})$ surfaces can be followed by using AM1 and PM3 semi-empirical methods. The major objective of this research is to compare between experiment adsorption results for the adsorption of linear alkyl benzene salfonate (LAS) on Iraqi Bentonite modifided by aquaternary aminonium salt (QAS) [1-Hexa decyl pyridinium bromide (HDPYBr)] and atheoretical study by using PM3 semi-empirical method for three quaternary ammonium salt; 1,12- Dipyridiniododecane dibromide (DPYDDBr 2 ), Hexadecyl trimethyl ammonium bromide(HDTMA) and 1- Hexadecyl pyridinium bromide (HDPYBr). The theoretical study involves calculating the adsorption efficiency for the three QAS, to adsorbing different aromatic pollutants like (phenol, phenolic compoundes, aniline and others).

\section{Materials and Methods Computational Calculation Semi-Empirical Method.}

Semi-Empirical Method PM3 is amodified neglect of diatomic orbital method-parameterized model 3 or MNDO-PM3.The calculations in this model are carried out efficiently. The method approximates inner shell electrons as a fixed core, and treats the valence electrons of an atom.

$\mathrm{E}=1 / 2 \Sigma_{\mathrm{ij}} \mathrm{P}_{\mathrm{ij}}\left(\mathrm{H}_{\mathrm{ij}}+\mathrm{F}_{\mathrm{ij}}\right)$

From this equation we calculate the electronic energy by using the density matrix $(P)$; Hamiltonian matrix $(H)$, includes the electric dipole term $\left(\mathrm{D}_{\mathrm{ij}}\right)$, and $\mathrm{F}$ is the Fock matrix . [10].

$\mathrm{H}_{\mathrm{ij}}=\mathrm{H}_{0, \mathrm{ij}}+\mathrm{E} \cdot \mathrm{D}_{\mathrm{ij}}$,

In each atom in the molecule,the basis set for the matrices is composed of the valence shell atomic orbitals, the core Hamiltonian matrix is sufficient to consider only the closed-shell orbitals $[11,12]$.

$\mathrm{H}_{\mu \mu}=\mathrm{U}_{\mu \mu}+\Sigma_{\mathrm{B}} \mathrm{V}_{\mu \mu, \mathrm{B}}$

$\mathrm{H}_{\mu \mathrm{v}}=\Sigma_{\mathrm{B}} \mathrm{V}_{\mu \mathrm{v}}$, B,

$\mathrm{H}_{\mu \lambda}=1 / 2\left(\beta_{\mu}^{\mathrm{A}}+\beta_{\lambda}^{\mathrm{B}}\right) \mathrm{S}_{\mu \lambda}$

The symbols $U_{\mu \mu}$ define the sum of the kinetic energy of the electron in orbital $\mu$, and the potential energy of the attraction between the electron and the atom core. The symbols $\mu$ and $\nu$ define the matrix elements of the atom A. The symbols $\lambda$ and $\sigma$ define denote atomic orbitals in an atom B. The potential energy $V_{\mu \mu, \mathbf{B}}$ define the attraction between the electron in atom $\mathrm{A}$ and the core of the atom B. The atomic orbitals represented by $\mu$ and $v$ in atom $\mathrm{A}$ are the charge distribution interactions between the spherical (s-type) charge distribution in atom $\mathrm{B}$, the type of atomic orbital is defined as $\beta$, The element from the overlap matrix is the element from the overlap matrix $S_{\mu v}$, The equations describe the Fock matrix for open shell, when the $\Phi$ represents the atomic orbitals is.

$\mathrm{F}^{\alpha}{ }_{\mu \mu}=\mathrm{H}_{\mu \mu}+\Sigma_{v_{v}}^{\mathrm{A}}\left[\mathrm{P}^{\alpha+\beta}{ }_{v v}\left(\Phi^{\mathrm{A}}{ }_{\mu} \Phi^{\mathrm{A}}{ }_{\mu}, \Phi^{\mathrm{A}}{ }_{v}\right.\right.$ $\left.\Phi^{\mathrm{A}}{ }_{v}\right)-\mathrm{P}^{\alpha}{ }_{v v}\left(\Phi^{\mathrm{A}}{ }_{\mu} \Phi^{\mathrm{A}}{ }_{v}, \Phi^{\mathrm{A}}{ }_{\mu} \Phi^{\mathrm{A}}{ }_{v}\right.$ )$]+\Sigma_{\mathrm{B}} \Sigma^{\mathrm{B}}{ }_{\lambda, \sigma} \mathrm{P}^{\alpha+\beta}{ }_{\lambda, \sigma}\left(\Phi_{\mu}^{\mathrm{A}}{ }_{\mu} \Phi^{\mathrm{A}_{\mu}}, \Phi^{\mathrm{B}}{ }_{\lambda} \Phi^{\mathrm{B}}{ }_{\sigma}\right)$.

(6)

$\mathrm{F}^{\alpha}{ }_{\mu \nu}=\mathrm{H}_{\mu v}+2 \mathrm{P}^{\alpha+\beta}{ }_{\mu v}\left(\Phi^{\mathrm{A}}{ }_{\mu} \Phi^{\mathrm{A}}{ }_{\nu}, \Phi^{\mathrm{A}}{ }_{\mu} \Phi^{\mathrm{A}}{ }_{\nu}\right)$ - $\mathrm{P}^{\alpha}{ }_{\mu \nu}\left[\left(\Phi^{\mathrm{A}}{ }_{\mu} \Phi^{\mathrm{A}}{ }_{\nu}, \Phi_{\mu}^{\mathrm{A}}{ }_{\mu} \Phi^{\mathrm{A}}{ }_{\nu}\right)+\left(\Phi^{\mathrm{A}}{ }_{\mu} \Phi_{\mu}^{\mathrm{A}}{ }_{\mu}\right.\right.$ ,$\left.\left.\Phi^{\mathrm{A}}{ }_{v} \Phi^{\mathrm{A}}{ }_{v}\right)\right]+\Sigma_{\mathrm{B}} \Sigma_{\lambda, \sigma}^{\mathrm{B}} \mathrm{P}^{\alpha+\beta}{ }_{\lambda, \sigma}\left(\Phi^{\mathrm{A}}{ }_{\mu} \Phi^{\mathrm{A}}{ }_{v}\right.$, $\Phi_{\lambda}^{\mathrm{B}} \Phi_{\sigma}^{\mathrm{B}}{ }_{\sigma}$.

$\mathrm{F}_{\mu \nu}^{\alpha}=\mathrm{H}_{\mu \lambda}-\Sigma^{\mathrm{A}}{ }_{\nu} \Sigma^{\mathrm{B}}{ }_{\sigma} \mathrm{P}^{\alpha}{ }_{\nu \sigma}\left(\Phi^{\mathrm{A}}{ }_{\mu} \Phi^{\mathrm{A}}{ }_{\nu}, \Phi^{\mathrm{B}}{ }_{\lambda}\right.$ $\Phi_{\sigma}^{\mathrm{B}}{ }_{\sigma}$ ).

In different atoms the interaction between orbitals on atom $\mathrm{A}$ and atom $\mathrm{B}$ 
approximate from electrostatic moments [10]. Semiempirical methods are the simplification of the Hamiltonian matrix by fitting them the experimental data [13-17]. The symbols $\mathrm{P}_{0}, \mathrm{~F}_{0}$, define the ground-state Fock and density matrices. The ground-state density matrix is then used as an input to the time-dependent stage [18].

Standard sparse-matrix for large systems can be used to efficiently do the Hartree-Fock (HF) iterations.

$$
P_{0}=\Phi\left(\mu-F_{0}\left(P_{0}\right)\right)
$$

\section{Results and Discussion:}

The adsorption of LAS on Iraqi bentonite was studied in previous experimental study [19] by using different LAS concentration different temperature and range of $\mathrm{PH}$. The modification of bentonite clay has been accomplished to activate its surface, and to get abetter adsorption process for the LAS molecules in the solution, where as the sorption (adsorption + absorption) on bentonite surface will also be abetter modifier that leads to vary the molecule orient in the pattern, and the adsorption is expected to be taken place at the external and internal surface. The sorption percentage of LAS on modified bentonite has significantly increased, due to the strong interaction between the LAS molecules and the modified surface, the sorption percentage exceeds $81 \%$, while the sorption of LAS on free bentonite clay at $298 \mathrm{~K}$ is about $36 \%$, so the modification process is profitable, It also increases the capacity of bentonite clay to accommodate LAS molecule on the surface of bentonite. Organoclay prepared [20] (bentonite-HDTMA) can remove phenol more efficiently than unmodified natural clay and the removal percentage reaches to $47 \%$ by amodified clay and $0.19 \%$ for the unmodified clay. The adsorption process obeying the Freundlich isothermal model and the kinetics is best explained by the pseudosecond order model[21]. In this study we use the PM3 semi-empirical method[22] (Zoebisch, Hedy and Stewart,1985) to calculate electronic density, geometrical optimizing shape, molecular orbital energy, dipole moment $(\mu)$ and Enthalpy of formation $\left(\Delta \mathrm{H}_{f}\right)$ for the three (QAS) and the organic pollutants.Fig. 1- a,b,c,d show the structures of bentonite and the three (QAS s) respectively. The structures of organic pollutants are given in Fig. 2 .

Table 1. gives the formula, molecular weight, enthalpy of formation $\left(\Delta \mathrm{H}_{f^{\circ}}\right)$ and HOMO (High occupied molecular orbitale), and LUMO (lowest unoccupied molecular orbitale) for the all pollutants and for the three QAS s respective.

The removal percentage $\mathrm{R} \%$ and energy barriers $\triangle \mathrm{E}$ between HOMO and LUMO of pollutants with QASs lead to increasing the adsorphion efficiency( $\mathrm{R} \%$ ) as shown in Table 2.

Fig. 3-5 show the HOMO and LUMO energy level for all pollutants with HDPYBr, DPYDDBr 2 and HDTMA respectively. The different energy between HOMO and LUMO levels $\triangle \mathrm{E}$ for each molecules reflects, the energy required to translate electron to the excited state (from HOMO to LUMO) [23, 24]. 


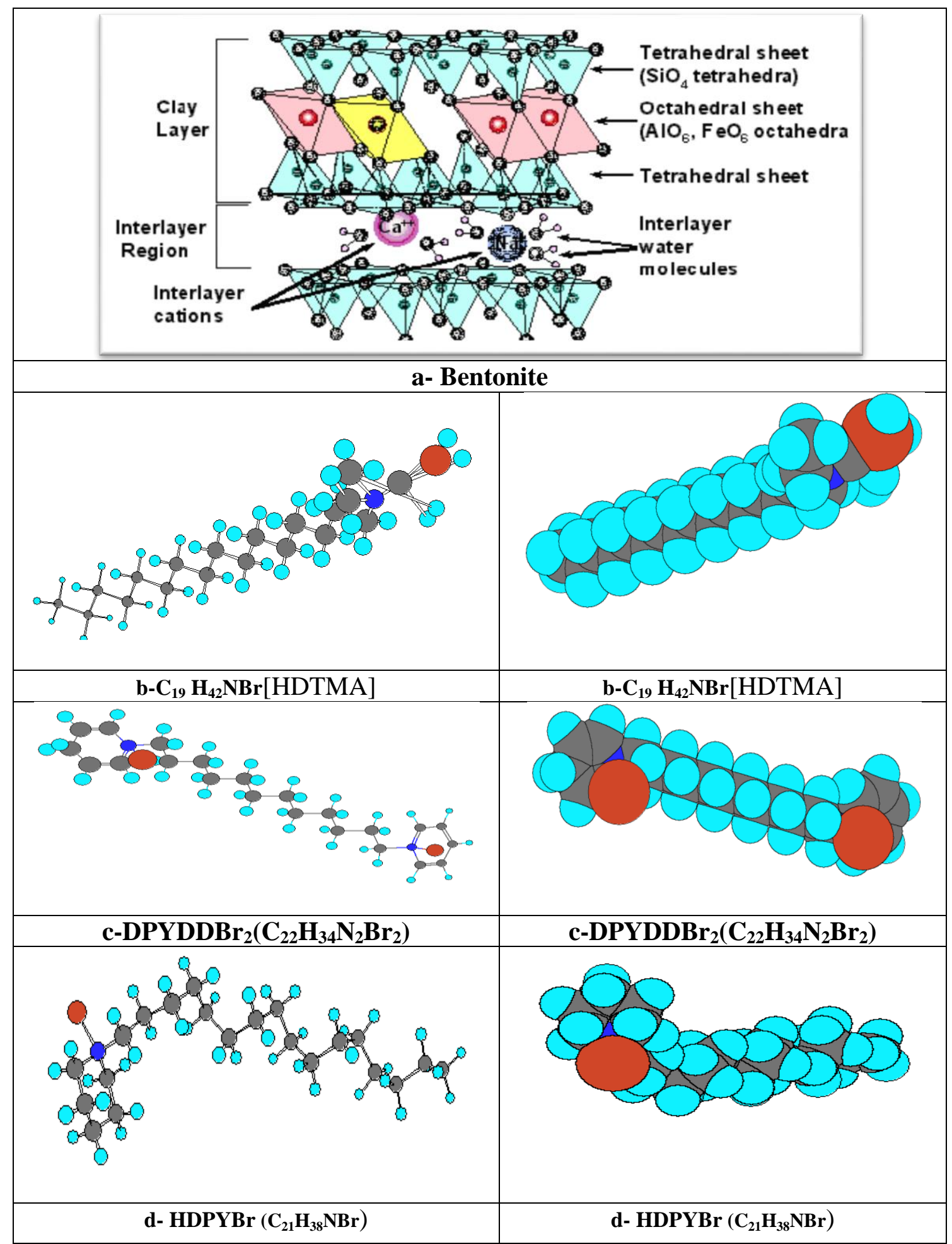

Fig. 1.The Structures of Bentonite and the Three (QAS s). 


LAS(lineuralkylbenzene

Fig. 2 . The Structures of Organic Pollutants. 
Table 1. The Formula, Molecular Weight, Enthalpy of Formation $\left(\Delta \mathbf{H}_{f}\right)$ and HOMO and LUMO for the All Pollutant and for the Three QAS s.

\begin{tabular}{|c|c|c|c|c|c|c|c|}
\hline Substance & Formula & $\begin{array}{l}\text { M.Wt. } \\
(\mathrm{g} / \mathrm{mol})\end{array}$ & $\Delta \mathbf{H}_{\mathrm{f}}(\mathrm{Kcal} / \mathrm{mol})$ & $\mu(D)$ & Homo(eV) & $\underset{(e V)}{\text { Lumo }}$ & $\begin{array}{c}\Delta \mathrm{E}(\text { Lumo } \\
- \text { Homo }) \\
(\mathrm{eV})\end{array}$ \\
\hline $\begin{array}{l}\text { LAS( linear alkyl benzene } \\
\text { salfonate) }\end{array}$ & $\mathrm{C}_{19} \mathrm{H}_{31} \mathrm{O}_{3} \mathrm{NaS}$ & 362.502 & -53.9338 & 41.2095 & -13.445 & -4.722 & 8.723 \\
\hline Phenol & $\mathrm{C}_{6} \mathrm{H}_{6} \mathrm{O}$ & 94.113 & -21.7505 & 1.1422 & -9.175 & 0.291 & 9.466 \\
\hline P -Nitro Phenol & $\mathrm{C}_{6} \mathrm{H}_{5} \mathrm{NO}_{3}$ & 139.110 & -31.8128 & 5.5665 & -10.170 & -1.081 & 9.089 \\
\hline p-Amino Phenol & $\mathrm{C}_{6} \mathrm{H}_{7} \mathrm{NO}$ & 109.127 & -23.3467 & 1.7397 & -8.346 & 0.305 & 8.651 \\
\hline P-Methyl phenol & $\mathrm{C}_{7} \mathrm{H}_{8} \mathrm{O}$ & 108.140 & -30.9933 & 1.2263 & -8.951 & 0.330 & 9.281 \\
\hline P-Chloro phenol & $\mathrm{C}_{6} \mathrm{H}_{5} \mathrm{OCl}$ & 128.558 & -28.4724 & 1.3946 & -9.009 & 0.048 & 9.057 \\
\hline Di-Chloro phenol & $\mathrm{C}_{6} \mathrm{H}_{4} \mathrm{OCl}_{2}$ & 163.003 & -34.0067 & 1.1667 & -9.038 & -0.185 & 8.953 \\
\hline Tri-Chloro phenol & $\mathrm{C}_{6} \mathrm{H}_{3} \mathrm{OCl}_{3}$ & 197.448 & -39.3440 & 1.6834 & -9.114 & -0.395 & 8.719 \\
\hline Titra-Chloro phenol & $\mathrm{C}_{6} \mathrm{H}_{2} \mathrm{OCl}_{4}$ & 231.893 & -43.4091 & 1.7676 & -9.051 & -0.584 & 8.467 \\
\hline pinta-Chloro phenol & $\mathrm{C}_{6} \mathrm{HOCl}_{5}$ & 266.338 & -48.3920 & 1.1045 & -9.136 & -0.789 & 8.347 \\
\hline Anilin & $\mathrm{C}_{6} \mathrm{H}_{7} \mathrm{~N}$ & 93.128 & 21.2158 & 1.296 & -8.610 & 0.418 & 9.028 \\
\hline Tri methyl Glycine & $\mathrm{C}_{5} \mathrm{H}_{12} \mathrm{NO}_{2}$ & 118.155 & -76.2347 & 2.2058 & -9.261 & 1.478 & 10.739 \\
\hline Ester of Sulphosuccinic acid & $\mathrm{C}_{4} \mathrm{H}_{6} \mathrm{O}_{6} \mathrm{~S}$ & 182.148 & -242.748 & 3.2030 & -11.057 & -0.837 & 10.22 \\
\hline $\begin{array}{c}\text { Lambdacy } \\
\text { holothrin(pesticide)(R)(Z)- } \\
\text { (IS)-Cis }\end{array}$ & $\mathrm{C}_{23} \mathrm{H}_{19} \mathrm{ClF}_{3} \mathrm{NO}_{3}$ & 449.900 & -9.763943 & 1.7382 & -9.515 & -0.289 & 9.226 \\
\hline $\begin{array}{c}\text { Lambdacy } \\
\text { holothrin(pesticide)(S)(Z)- } \\
\text { (IR)-Cis }\end{array}$ & $\mathrm{C}_{23} \mathrm{H}_{19} \mathrm{ClF}_{3} \mathrm{NO}_{3}$ & 449.900 & -4.305926 & 2.3758 & -9.376 & -0.361 & 9.015 \\
\hline $\begin{array}{c}\text { HDTMA } \\
\text { (Hexadecyltrimethyl } \\
\text { ammonium bromide) }\end{array}$ & $\mathrm{C}_{19} \mathrm{H}_{42} \mathrm{NBr}$ & 364.452 & 12.643015 & 4.0366 & -8.368 & 0.769 & 9.137 \\
\hline $\begin{array}{l}\text { HDPYBr (1- Hexadecyl } \\
\text { pyridinium bromide) }\end{array}$ & $\mathrm{C}_{21} \mathrm{H}_{38} \mathrm{NBr}$ & 389.481 & -99.120064 & 4.5317 & -9.771 & 1.799 & 11.570 \\
\hline $\begin{array}{c}\text { DPYDDBr }_{2} \\
\text { 1,12- Dipyridiniododecane } \\
\text { dibromide }\end{array}$ & $\mathrm{C}_{22} \mathrm{H}_{34} \mathrm{~N}_{2} \mathrm{Br}_{2}$ & 486.332 & 63.70714 & 2.0496 & -8.799 & -0.629 & 8.170 \\
\hline
\end{tabular}


Table 2. The Value of Percentage $R \%$ Remover and Energy Barriers $\Delta E$ between HOMO and LUMO of Pollutants with QASs .

\begin{tabular}{|c|c|c|c|c|c|c|}
\hline Substance & R\%-HDTMA & $\begin{array}{c}\Delta \text { E(LUMO- } \\
\text { HOMO) }\end{array}$ & $\begin{array}{c}\text { R\%- } \\
\text { DPYDDBr }_{2}\end{array}$ & $\begin{array}{c}\Delta \text { E(LUMO- } \\
\text { HOMO) }\end{array}$ & $\begin{array}{c}\text { R\%- } \\
\text { HDPYBr }\end{array}$ & $\begin{array}{c}\Delta \text { E(LUMO- } \\
\text { HOMO) }\end{array}$ \\
\hline $\begin{array}{c}\text { LAS( lineur alkyl } \\
\text { benzene salfonate)(1) }\end{array}$ & 112.169 & 3.646 & $100.00^{* *}$ & 8.723 & $81.000^{* *}$ & 5.049 \\
\hline Phenol (2) & $47.231^{* *}$ & 8.659 & 47.855 & $8.546^{*}$ & 40.645 & 10.062 \\
\hline P -Nitro Phenol (3) & 56.123 & 7.287 & 52.989 & 7.718 & 47.062 & 8.690 \\
\hline p-Amino Phenol (4) & 47.154 & 8.673 & 52.996 & $7.717^{*}$ & 40.588 & 10.076 \\
\hline P-Methyl phenol (5) & 47.019 & 8.698 & 49.143 & 8.322* & 40.488 & 10.101 \\
\hline P-Chloro phenol (6) & 48.594 & 8.416 & 48.803 & $8.38^{*}$ & 41.651 & 9.819 \\
\hline Di-Chloro phenol(7) & 49.978 & 8.183 & 48.635 & 8.409* & 42.663 & 9.586 \\
\hline Tri-Chloro phenol(8) & 51.294 & 7.973 & 48.664 & 8.404 & 43.619 & 9.376 \\
\hline Titra-Chloro phenol(9) & 52.540 & 7.784 & 49.783 & 8.215 & 44.516 & 9.187 \\
\hline pinta-Chloro phenol(10) & 53.961 & 7.579 & 49.037 & 8.347 & 45.532 & 8.982 \\
\hline Anilin(11) & 46.549 & 8.786 & 51.243 & $7.981 *$ & 40.138 & 10.189 \\
\hline Tri methyl Glycine(12) & 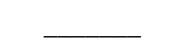 & $9.846^{*}$ & 47.378 & $8.632 *$ & 36.977 & 11.249 \\
\hline $\begin{array}{c}\text { Ester of Sulphosuccinic } \\
\text { acid(13) }\end{array}$ & 54.305 & 7.531* & 51.579 & 7.929 & 41.855 & 9.771 \\
\hline $\begin{array}{c}\text { Lambdacy } \\
\text { holothrin(pesticide)(14) }\end{array}$ & 50.621 & 8.079* & 48.058 & 8.510 & 43.131 & 9.482 \\
\hline $\begin{array}{c}\text { Lambdacy } \\
\text { holothrin(pesticide) (15) }\end{array}$ & 51.076 & $8.007^{*}$ & 48.468 & 8.438 & 43.461 & 9.410 \\
\hline
\end{tabular}

(**) Experimental results. [19].

$\left(^{*}\right)$ The process is from pollutants to modified $(\mathrm{P} \rightarrow \mathrm{M})$. The rest $\Delta \mathrm{E}$ is from modified to pollutants $\mathrm{M} \rightarrow \mathrm{P}$

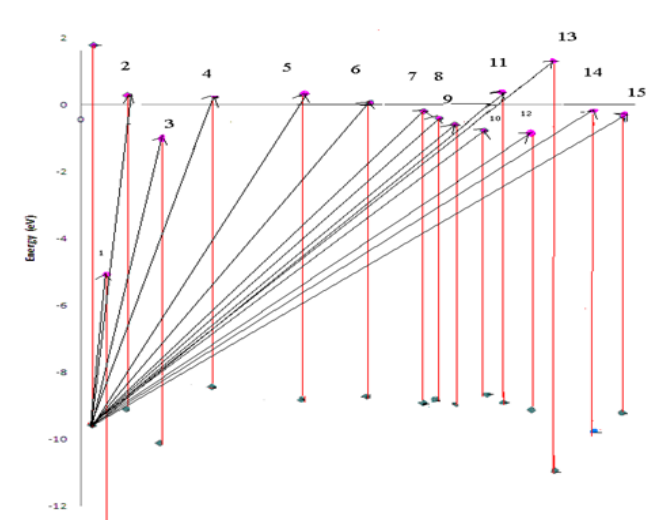

Fig.3. Correlation Digram of HOMO and LUMO Energy Levels for HDPYBr $\left(\mathrm{C}_{21} \mathrm{H}_{38} \mathrm{NBr}\right)$ and All Pollutants.

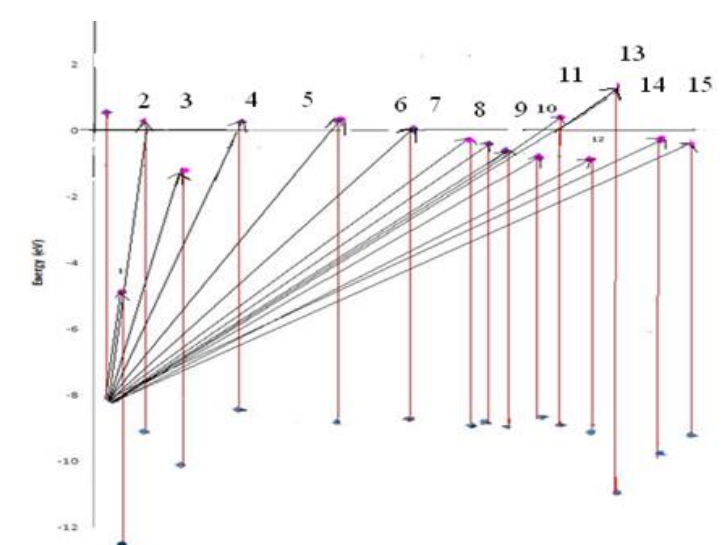

Fig.4. Correlation Digram of HOMO and LUMO Energy Levels for HDTMA $\left(\mathrm{C}_{19} \mathrm{H}_{42} \mathrm{NBr}\right)$ and All Pollutants. 


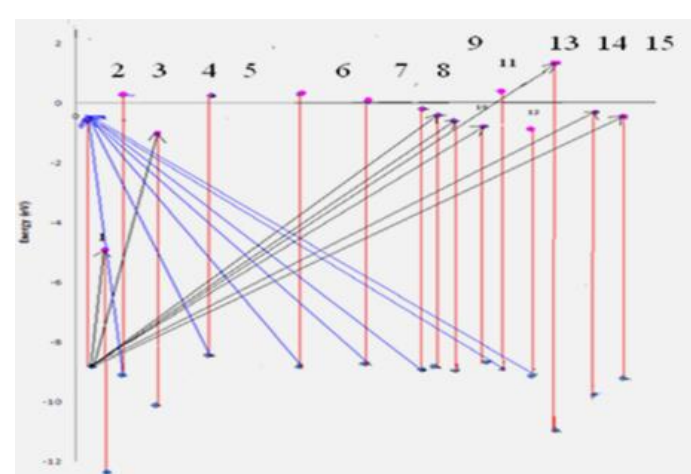

Fig.5. Correlation Digram of HOMO and LUMO Energy Levels for DPYDDBr $_{2}\left(\mathrm{C}_{22} \mathrm{H}_{34} \mathrm{~N}_{2} \mathrm{Br}_{2}\right)$ and All Pollutants.

Modification Bentonite surface with QASs, leads to remove water molecules from the silicate layer and alkyl chains Hydrophobic interactions lead the hydroxyl and/or oxygen adsorped on sites standby water molecules. The Hydrophobic interactions are generally weaker than polar interactions as well as the hydrogen bonds, which can be expected to take part between the silicate sheets and the phenol hydroxyl group due to the perpendicular orientation of phenol.

The lower uptake of phenol by bentonite can be explained by lindrance of strongly adhered water molecules to the silicate surface. The adsorption of the water and phenol molecules is compelitive in this case (6). The hydrophobised surface causes the higher phenol adsorption on modified bentonite than on the original bentonite. The $\Delta \mathrm{E}$ values between all pollutants and the three QASs reflect the energy required to translate electron between HOMO of the molecule to LUMO of the other molecule which leads to the interaction occuring between the pollutant molecule and QASs as modifier. The lowest value of $\triangle \mathrm{E}$ leads to the highest adsorption efficiency [23, 24], so (HDTMA) gives the highest $(\mathrm{R} \%)$ for LAS which transcends 100\%,this means that the modified clay surface with HDTMA increases the adsorption capacity. From the experimental adsorption results HDTMA leads to the adsorpted $47.2 \%$ of phenol and by comparing this value with the different energy levels in Fig. 3,4 ,The expected efficiency for the three QASs are calculated in (Table 3).

The efficiency of HDPYBr is as fellows: LAS( lineur alkyl benzene salfonate)> $\mathrm{P}$ -Nitro Phenol> Titra-Chloro phenol> Tri-Chloro phenol> LAMBDACY> Lambdy> Di-Chloro phenol> Ester of Suphosuccinic acid $>$ P-Chloro phenol $>$ phenol > p-Amino Phenol > P-Methyl phenol >Anilin> Tri methyl Glycine Whene as the order of efficiencies of HDTMA are as follow:

LAS (lineur alkyl benzene salfonate) > P -Nitro Phenol > Ester of Suphosuccinic acid > pinta-Chloro phenol > TitraChloro phenol > Tri-Chloro phenol > LAMBDACY > Lambdy > Di-Chloro phenol $>$ P-Chloro phenol $>$ phenol $>$ pAmino Phenol > Tri methyl Glycine

At last the order of the efficiencies of $\mathrm{DPYDDBr}_{2}$ is:

LAS (lineuralkyl benzene salfonate) > PChloro phenol >Ester of Sulphosuccinic acid > Anilin

\section{Conclusions:}

Certain conclusions can be derived from the results and discussions as in the following:

Modified bentonite with QASs lead to remove water molecules from silicate layers and replace it by hydroxyl and /or oxygen molecules. This interaction bettween alkyl chains and silicate layers is generally considered to be weaker than polar ones as well as the hydrogen bonds formation. It can be expected that some hydrogen bonds can take place between the silicate sheet and organic pollutants. Semi-empirical method (PM3) calculation is successful by comparing the data with the experimental study by using modifier molecules like anionic or cationic surfactant and the best modifier can be selected theoretically. 


\section{References:}

[1]Frost, R. L.; Zhoua, Q.; He, H. and Xi, Y. 2008. An infrared study of adsorption of Para-Nitrophenol on Mono-,di-and tri-Alkyl surfactant intercalated Organo Clys Spectro Chimical Acta partA,69(6):239-244.

[2]Xi, Y.; He, H. and Frost, R. L. 2004. Structure of Organo Clays-an X-Ray diffraction and Thermogravimetric Analysis Study. J. of Colloid and interface Sci., 277(1);116-120.

[3]Boydsa, S. S.; Lee, J. F. and Mortland, M. M. 1988. Penta Chlorophenol Sorption by OrganoClays and Clay minerals, 36(4):125130.

[4]Xi, Y.; Frost, R. L.; He, H. and Kloprogge, T. 2005. Modification of Wyoming Montmorillonite Surfaces using Actionic Surfactant Langmuir, 21(3):8675-8680.

[5]Xu, L. and Zhu, 1. 2009. Structures of OTMA and DODMA Bentonite and their Sorption Characteristics towards Organic Compounds. J. Of Colloid and Interface Sci.,331(11):8-14.

[6]Zhu, L.; Chen, B. and Shen, X. 2000. Sorption of Phenol, p-Nitro Phenol, and Aniline todual cation Organo Bentonites from Water. J. E. S., 34(4):648-475.

[7]Julian, and Gate, D. 1997. SemiEmpirical Methods as Atool in SolidState Chemistry Faraday Discuss., 106(10):219-232.

[8]Jon, K.; West, J.R.; Robert; Larry, L. and Hench. 1997. Molecular Modeling Study of Adsorption of poly-L-lysine onto silica glass J. B. M. R. Part A.37 (4): 585-591.

[9]Joao, B. L.; Martianws; Jun; Anders; Elswon and Taft, C. A. 1998. Properties, Dynamics, and Electronic Structure of Condensed Systems $\mathrm{H}_{2} \mathrm{O}$ and $\mathrm{H}_{2}$ Interaction with $\mathrm{ZnO}$ Surfaces: A MNDO, AM1, and PM3 Theoretical Study with Large cluster Models Int. J. Quant. Chem.,57:(5) :861-870.
[10] Dewar, M. J. S. and Thiel W. 1977. Thiel and A. Voityuk. Extension of MNDO to d-Orbitals Parameters and results for the 2 nd ... Theor. Chim. Acta., 46 (56): 89 -104 . [11] Dewar, M. J. S. and Thiel, W. 1977. Ground States of Molecules, The MNDO method. Approximations and Parameters. J. Am. Chem. Soc., 99 (8): 4899.

[12] Stewart, J. J. P. 1989. Optimization of Parameters for SemiEmpirical Methods II. Applications. J. Comput. Chem. 10 (2): 221.

[13] Stewart, J. J. P. 1990. Molecular Mechanics. The MM3 Force Field for Hydrocarbons. J. Comput.-Aided Mol. Des., 4, 1-105.

[14] Stewart, R. F. 1970. Inversion of Molecular Spectra by Solid Environments . J. Chem. Phys., 52(8): 431.

[15] Dewar, M. J. S.; Zoebisch, E. G.; Healy, E. F. and Stewart, J. J. P. 1985. The Development and use of ... Mechanical Molecular Model. J. Amer. Chem. Soc. 107 (9):3902-9.

[16] Bingham, R. C., Dewar, M. J. S. and Lo, D. H. 1975. Calculation of nonlinear optical coefficients for lithium formate .. J. Am. Chem. Soc., 97(8): 1285.

[17] Stewart, J. J. P. 1989. Article Optimization of Parameters for Semi Empirical Methods I. J. Comput Chem., 2 (10): 209-220.

[18] Stewart, J. J. P. 1991. Optimization of Parameters for SemiEmpirical Methods. III Extension. J. Comput. Chem., 3 (12):320-341.

[19] AL-Meamon, A. A. 2007. Adsorption Studius of linear Alkylbenzene Sulfonate by using Iraqi Bentonite Clays M.Sc. Thesis, College of Science, University of Baghdad., 60-67.

[20] Boiny, S.; Xi.; Yunfei, M. M.; Krishnamurti, G. S. R. and Ravi, N. 
2010. Adsorption of Phenol by HDTMA- Modified Organo Clay. 486(30):5106.

[21] Hana, K.; Peter, P. and Martina, T. 2008. Adsorption of Phenol and Aniline by Original and aternary Ammonium Salts-Modified Montmorillonite. Acta Geodyn. Geomater., 1(6): 83-88.

[22] Zoebisch, E. G.; Hedy, E. F. and Stewart, J. J. P. 1985. Molecular
Orbital Calculations by Using Aml Semi-Empirical Methods. J. A. Chem. Soc., 107(23): 3902.

[23] د.صالح، جلال محمد. و الصدر، باسل هانشم. 1989. الدينمية الكيميائية و الكيمياء

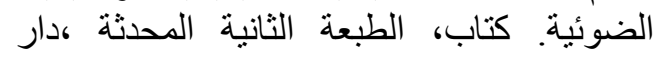

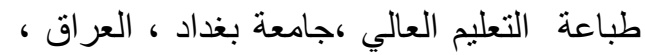
332-227

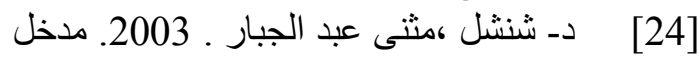
لميكانيك الكم. كتاب الطبعة الثانية، مطبعة كلية

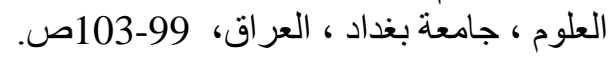

\section{دراسة شبه التجريبية لامتزاز بعض الملوثات العضوية على الاطيان العراقية المحسنة}

هدى نجم الدين العاني

خلود عبد صالح السعدي

قسم الكيمياء ، كلية العلوم ، جامعة بغداد، جادرية، بغداد، العراق

في هذا البحث تم استعمال الطرائق شبه التجريبية بطريقة (PM3) باستخدام برنامج (MOPAC)

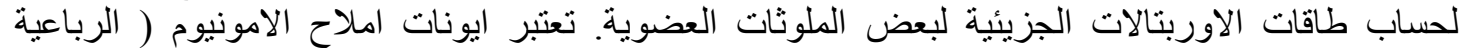

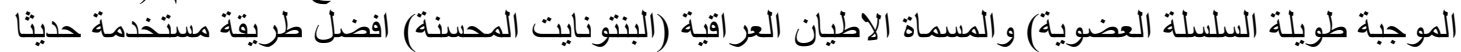

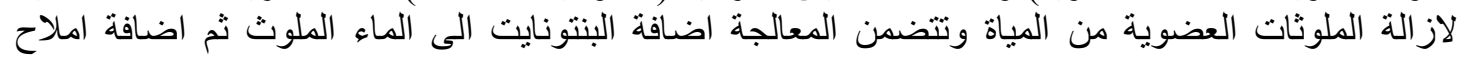

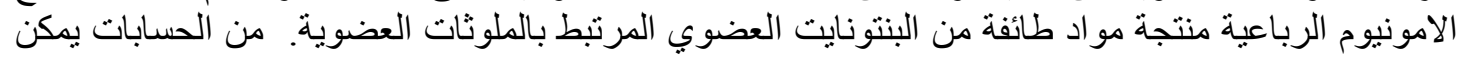

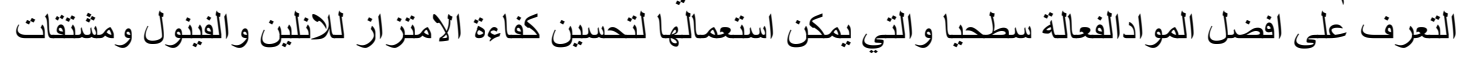

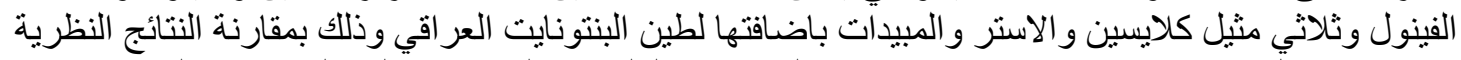

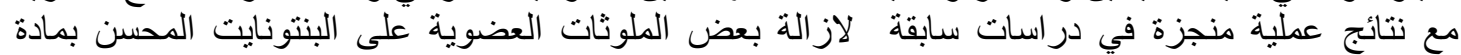

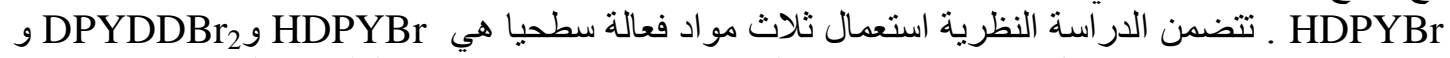
HDTMA

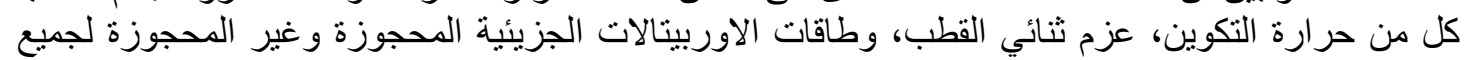

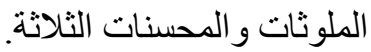

الكلمات المفتاحية: طر ائق الحساب شبة التجريبية بطريقة (PM3)، امتزاز املاح الامونيوم الرباعية، الطين العر اقي(البنتونايت ــ العضوية طرائ). 